\title{
A New Measure of Population Health in a Complex Sampling Survey: The 2019 Georgia Behavioral Risk Factor Surveillance Survey - Unweighted, Weighted, and Imputed Weighted Data
}

Changle Li

University of Georgia

Toni Miles ( $\boldsymbol{D}$ tonimile@uga.edu )

University of Georgia

Ye Shen

University of Georgia

Rana Bayakly

Georgia Department of Public Health

Moses Ido

Georgia Department of Public Health

M Mahmoud Khan

University of Georgia

\section{Research Article}

Keywords: BRFSS, Bereavement, Grief, Loss, Population Surveillance, Weighting, Multiple Imputation, Public Health

Posted Date: September 2nd, 2021

DOl: https://doi.org/10.21203/rs.3.rs-793157/v1

License: (c) (i) This work is licensed under a Creative Commons Attribution 4.0 International License. Read Full License 


\section{Abstract}

Background: Measuring population health requires a well-defined denominator. The Behavioral Risk Factor Surveillance Survey (BRFSS) is designed to provide one for state-level populations. In 2019, the U.S. state of Georgia tested a new module to study recent bereavement among its 8.1 million residents aged 18 years and older. This is the first population-level assessment of bereavement. In BRFSS, bereavement is defined as the fact of a death. The term grief is not used because it denotes emotions related to that death. There is evidence from cohort studies linking new bereavement to subsequent mortality and health care utilization.

Methods: BRFSS data are obtained using list-assisted, random digit dialing from the non-institutionalized population aged 18 years and older within primary statistical units. Data came from both landline telephones and cellular phones. Three questions were added to the end of the latest BRFSS asking about death of family or friend in 2018 or 2019. To evaluate data from this new module, the report presents three statistical approaches - unweighted panel data, weighted data, and weighted data using multiple imputation of missing responses. The estimated prevalence of bereavement and its standard error under each data scenario is calculated.

Results: The threat to the validity of data from this new module are bias due to small samples and missingness. The unweighted panel contains 5,206 persons (70.9 percent response). Among these, 2,396 persons (46.0\%) responded 'Yes' to 'Have you experienced the death of a family member or close friend in the years 2018 or 2019 ? To estimate the size of the population, weights are applied. With weighted data and removal of missing responses yields a prevalence of $45.56 \%(\mathrm{SE}=1.13)$ with a population estimate of 4,937,056 persons. Using multiple imputation to keep missing responses, the prevalence is $45.80 \%(S E=1.18)$ with a denominator of $8,164,018$ persons.

Conclusions: New bereavement can be ascertained in a surveillance survey without bias due to refusals. Multiple imputation provides a population size estimate that is comparable to U.S. Census bureau. More field testing is required to replicate these results in other states.

\section{Background}

Measuring population health requires an account of the total population, in addition to the subset with the characteristics of interest. Plainly stated, a well-defined denominator is critical to this measurement. The Behavioral Risk Factor Surveillance Survey (BRFSS) is a collaboration between geopolitical units (state departments of public health) and the federal government (Centers for Disease Control and Prevention) to generate a denominator for adults aged 18 years and older. Healthy People is a product that uses BRFSS to assess progress towards national public health objectives. An infographic How to use Healthy People is available in a supplemental file.

The measurement of population health is a dynamic process. Its surveillance requires flexibility as new threats emerge. BRFSS operationalizes this aim by combining a national common core items with an 
option for each state to add items of specific interest. The history of BRFSS is included in a supplement file BRFSS History. During the 2019 BRFSS the state of Georgia added a special module containing 3 items targeting new bereavement. Bereavement is a term to define the fact of a death. The term grief is not used because it denotes emotions related to that death. It is possible to be bereaved but not grieving. According to the Georgia Department of Public Health, there were 134,905 combined deaths in 2018 and 2019. Before the 2019 Georgia BRFSS, there were no population health estimates of bereavement among adults aged 18 years and older.

This report presents data from the new bereavement module. The supplemental files contain the specific survey questions asked - 2019 Georgia BRFSS QUESTIONNAIRE. These data are shown under different sample treatment scenarios - unweighted panel, sample weighting, and weighted sample with multiple imputation of missing reports. These are three common scenarios serving a variety of purposes. Unweighted panel data are commonly used to create multivariate models to measure strength of association in adjusted models. ${ }^{1,2}$ Weighted data are used to develop resource requirements. ${ }^{3}$ The first two scenarios do not adjust for missing responses. By combining sample weights with multiple imputation techniques, bias reduction and precision improvement may be obtained. ${ }^{4.5}$

\section{Methods}

\section{Sample}

Table 1 shows the size of the unweighted sample responding to the common core items $(n=7,354$ maximum) and the new bereavement item $(n=5,206)$. The BRFSS data are obtained in telephone interviews. Georgia has been part of the system since 1984. Using list-assisted, random digit dialing, respondents are randomly selected from the non-institutionalized adult population aged 18 years and older from each household within primary statistical units. Data came from both respondents who had landline telephones and those who frequently use cellular phones. BRFSS contains uniform, state-specific data on health risk behaviors, chronic diseases, access to health care, and use of preventive services related to the leading causes of death and disability through its common core. These items were selected to create the categories shown in Table 1 - Demographics, Social Determinants, and Health Behaviors and shows the number of participants with complete or missing responses to each item in rows. The last row in the table shows the sample size available to an analyst creating adjusted multivariate models $(\mathrm{n}=$ 4,289). 
Table 1

Variables used in this analysis, 2019 Georgia BRFSS, Unweighted Panel

\begin{tabular}{|c|c|c|c|c|}
\hline Variable & $\begin{array}{l}\text { Complete } \\
\text { Response, } \\
\text { N }\end{array}$ & $\begin{array}{l}\text { Complete } \\
\%\end{array}$ & $\begin{array}{l}\text { Missing } \\
\text { Response, } N\end{array}$ & $\begin{array}{l}\text { Missing } \\
\%\end{array}$ \\
\hline Bereavement item*: & 5,206 & 70.79 & 2,148 & 29.21 \\
\hline \multicolumn{5}{|l|}{$\begin{array}{l}\text { Loss of family or friend in } 2018 \text { or } \\
2019 \text {. }\end{array}$} \\
\hline \multicolumn{5}{|l|}{ Demographics } \\
\hline Gender & 7,354 & 100.00 & 0 & 0 \\
\hline SOG|§ & 5,443 & 74.01 & 1,911 & 25.99 \\
\hline Age & 7,354 & 100.00 & 0 & 0 \\
\hline Race / ethnicity & 7,180 & 97.63 & 174 & 2.37 \\
\hline \multicolumn{5}{|l|}{ Social determinants } \\
\hline Educational attainment & 7,319 & 99.52 & 35 & 0.48 \\
\hline $\begin{array}{l}\text { Metropolitan Statistical Area, } \\
\text { residence }\end{array}$ & 7,354 & 100.00 & 0 & 0 \\
\hline Employment status & 7,202 & 97.93 & 152 & 2.07 \\
\hline \multicolumn{5}{|l|}{ Health Behaviors } \\
\hline Physical activity in past month? & 6,780 & 92.19 & 574 & 7.81 \\
\hline Smoking status & 6,847 & 93.11 & 507 & 6.89 \\
\hline $\begin{array}{l}\text { At least one drink of alcohol in past } \\
30 \text { days? }\end{array}$ & 6,796 & 92.41 & 558 & 7.59 \\
\hline Multiple drinks on one occasion & 6,540 & 88.93 & 814 & 11.07 \\
\hline Self-rated health & 7,330 & 99.67 & 24 & 0.33 \\
\hline $\begin{array}{l}\text { Physical Health not good, days in } \\
\text { past month }\end{array}$ & 6,802 & 92.49 & 552 & 7.51 \\
\hline $\begin{array}{l}\text { Mental Health not good, days in past } \\
\text { month }\end{array}$ & 6,799 & 92.45 & 555 & 7.55 \\
\hline
\end{tabular}

Note: 'Don't know', 'Refused' and 'Blank' equal missing. *New 2019 BRFSS item 'Have you experienced the death of a family member or close friend in the years 2018 or 2019? * SOG|s: Sexual Orientation and Gender Identity. Module 29, two questions ' Which of the following best represents how you think of yourself? Do you consider yourself to be transgender? Health behaviors reflect Healthy People 2020 target areas described in https://www.healthypeople.gov/2020/topics-objectives ; Accessed April 11, 2021. For all items see 2019 BRFSS Questionnaire https://www.cdc.gov/brfss/questionnaires/index.htm; Accessed May 14, 2021. 


\begin{tabular}{|c|c|c|c|c|}
\hline Variable & $\begin{array}{l}\text { Complete } \\
\text { Response, } \\
\text { N }\end{array}$ & $\begin{array}{l}\text { Complete } \\
\%\end{array}$ & $\begin{array}{l}\text { Missing } \\
\text { Response, N }\end{array}$ & $\begin{array}{l}\text { Missing } \\
\%\end{array}$ \\
\hline $\begin{array}{l}\text { Complete information above } 15 \\
\text { variables }\end{array}$ & 4,289 & 58.32 & 3,065 & 41.68 \\
\hline \multicolumn{5}{|c|}{$\begin{array}{l}\text { Note: 'Don't know', 'Refused' and 'Blank' equal missing. *New } 2019 \text { BRFSS item 'Have you experienced } \\
\text { the death of a family member or close friend in the years } 2018 \text { or } 2019 \text { ? * SOGI\$: Sexual Orientation } \\
\text { and Gender Identity. Module } 29 \text {, two questions 'Which of the following best represents how you think } \\
\text { of yourself? Do you consider yourself to be transgender? Health behaviors reflect Healthy People } \\
2020 \text { target areas described in https://www.healthypeople.gov/2020/topics-objectives; Accessed } \\
\text { April 11, 2021. For all items see } 2019 \text { BRFSS Questionnaire } \\
\text { https://www.cdc.gov/brfss/questionnaires/index.htm; Accessed May 14, } 2021 \text {. }\end{array}$} \\
\hline
\end{tabular}

\section{Measures}

\section{New measure: Recent bereavement}

The 2019 Georgia BRFSS added a new module containing 3 items on the topic of Bereavement. Participants were asked 'Have you experienced the death of a family member or close friend in the years 2018 or 2019 ? There were 7,354 persons responding to the common core questions and a subset of 5,206 persons from this larger group in the bereavement module (29.2 percent). All participants answer yes or no - there were no refusals. When the answer was yes, participants were queried about the number of losses and their relationship to the decedent. Sixty-five percent of this sample reported the death of a family member.

\section{Demographic variables: Age, Race / Ethnicity, Gender / Sexual Orientation}

These items are a part of the common core questions asked by all states. The GA BRFSS also has three items asking about sexual orientation and gender identity. To define sexual orientation participants were asked: Which of the following best represents how you think of yourself, and do you consider yourself to be transgender? Response options are: Gay, Straight or Bisexual or Something else. Response options for the transgender question are: Transgender male to female, Transgender female to male, transgender nonconforming.

\section{Social determinants of health: Education, Residence in Metropolitan County, Employment}

These items are also a part of the common core questions asked by all states. The following social determinants of health associated with bereavement are educational attainment (four level), residence was dichotomized as metropolitan county versus nonmetropolitan counties, and employment status (five levels). 


\section{Health behavior variables: Physical activity, smoking, alcohol consumption, self-rated health, physical / mental health}

Health behavior is traditionally the target of public health action. Individual behaviors are part of the common core asked by all states. The variables listed in Table 1 were used to explore biases created by missingness and the effect of applicating imputation techniques. This table shows the variation in missing responses across items. There are several items with no missing responses (gender, age), low missing response rates (education, self-rated health) and intermediate missing (race, health behaviors). Finally, Sexual orientation and gender (SOGI) and bereavement have the highest rates of missing responses.

\section{Multiple imputation of missing data}

The last row in Table 1 shows 4,289 respondents with complete information on all 15 items of interest for use in multivariate modeling. Analysts are faced with choices ranging from excluding persons with missing data to applying multiple imputation techniques. There are three fundamental missing-data techniques: missing completely at random (MCAR), missing at random (MAR), and missing not at random (MNAR). MCAR occurs when the missingness is unrelated to the observed and unobserved value for that unit. ${ }^{6}$ Under a MAR mechanism, the probability of a missing value for an item may depend on observed data but not on unobserved data. MNAR means that the probability of missingness depends on the underlying value of an item. ${ }^{7}$

Multiple imputation is a simulation-based statistical technique and allows researchers to use more available data, thus reducing biases when observations with missing data are deleted. ${ }^{8}$ Multiple imputation has three elemental phases: imputation, analysis, and pooling. The imputation phase is to create $m$ copies of the dataset, with the missing values replaced by imputed values using an appropriate model. Rubin suggested that $m=5$ should be sufficient to obtain valid inference, while some researchers reported $m$ should be 50 or more..$^{-12}$ We chose to create 50 copies to reduce the sampling error due to imputations. The imputation process was carried out based on multiple imputation by chained equations (MICE). The MICE is a practical approach to impute missing data in multiple variables based on a set of univariate imputation models. ${ }^{13}$ We selected the conditional models based on the type of variables. The MICE allow the use of logistic regression model to impute binary variables such as bereavement. Moreover, ordered logistic and multinomial logistic regression models can impute ordered categorical such as educational attainment and unordered categorical variables such as race

For this analysis, the MCAR assumption was regarded as not plausible based on the MCAR test (data not shown). Instead, we adopted the MAR assumption. There are several causes for missing data. In addition to refusal to answer, the bereavement item's missing data can result from the respondents moving to other states away from Georgia and ending the interview before getting to the final module. 
In this phase, each of the 50 complete datasets were analyzed using a desired statistical method. The results obtained from 50 completed datasets are combined into a single multiple-imputation result in the pooling phase. ${ }^{12}$ The single parameter estimate is the mean of the 50 parameter estimates. Standard error is calculated based on Rubin's rules. ${ }^{9}$

\section{Results}

The unweighted panel data shown in Table 2 provides additional detail for prevalence of bereavement within subgroups. Each row shows the unweighted number of respondents for categories of bereavement. In the unweighted panel, the prevalence of bereavement ' $Y e$ s' $^{\prime}$ within subgroup row ranges from 37.65 percent to 54.98 percent.

Table 2: Complete response to Bereavement item, Subgroups, 2019 Georgia BRFSS, Unweighted Panel 


\begin{tabular}{|c|c|c|c|c|}
\hline & $\begin{array}{l}\text { Respo } \\
N=5,2\end{array}$ & e to Berea & ment & \\
\hline & Yes & & No & \\
\hline & $N=2,3$ & & $\mathrm{~N}=2$ & \\
\hline & $\mathbf{N}$ & Percent & $\mathbf{N}$ & Percent \\
\hline Demographics & & & & \\
\hline Males $(N=2,260)$ & 992 & 43.89 & 1,268 & 56.11 \\
\hline Females $(\mathrm{N}=2,946)$ & 1,404 & 47.66 & 1,542 & 52.34 \\
\hline SOG|s: CIS Gender $(N=4,788)$ & 2,235 & 46.68 & 2,553 & 53.32 \\
\hline SOG|S: All other $(\mathrm{N}=281)$ & 125 & 44.48 & 156 & 55.52 \\
\hline $18-24$ years $(N=322)$ & 124 & 38.51 & 198 & 61.49 \\
\hline $25-34$ years $(N=507)$ & 216 & 42.60 & 291 & 57.40 \\
\hline $35-44$ years $(N=628)$ & 304 & 48.41 & 324 & 51.59 \\
\hline $45-54$ years $(N=749)$ & 361 & 48.20 & 388 & 51.80 \\
\hline $55-64$ years $(N=1,044)$ & 508 & 48.66 & 536 & 51.34 \\
\hline $65+\operatorname{years}(N=1,956)$ & 883 & 45.14 & 1,073 & 54.86 \\
\hline Black or African American only, $\mathrm{NH}^{€}(\mathrm{~N}=1,084)$ & 596 & 54.98 & 488 & 45.02 \\
\hline White only, $\mathrm{NH}^{€}(\mathrm{~N}=3,423)$ & 1,533 & 44.79 & 1,890 & 55.21 \\
\hline All other $(N=595)$ & 224 & 37.65 & 371 & 62.35 \\
\hline Social determinants & & & & \\
\hline Metropolitan Statistical Area, Yes $(\mathrm{N}=3,628)$ & 1,641 & 45.23 & 1,987 & 54.77 \\
\hline Metropolitan Statistical Area, No $(\mathrm{N}=1,578)$ & 755 & 47.85 & 823 & 52.15 \\
\hline Graduated, College or Technical School $(N=1,792)$ & 781 & 43.58 & 1,011 & 56.42 \\
\hline Attended College or Technical School $(N=1,447)$ & 701 & 48.45 & 746 & 51.55 \\
\hline Graduated, High School $(N=1,357)$ & 643 & 47.38 & 714 & 52.62 \\
\hline Did not graduate, High School $(\mathrm{N}=593)$ & 262 & 44.18 & 331 & 55.82 \\
\hline Employed $(\mathrm{N}=2,300)$ & 1,055 & 45.87 & 1,245 & 54.13 \\
\hline Unemployed ( $N=218)$ & 114 & 52.29 & 104 & 47.71 \\
\hline Retired $(N=1,680)$ & 760 & 45.24 & 920 & 54.76 \\
\hline
\end{tabular}




\begin{tabular}{lllll} 
Unable to work $(\mathrm{N}=541)$ & 268 & 49.54 & 273 & 50.46 \\
\hline Homemaker or student $(\mathrm{N}=432)$ & 187 & 43.29 & 245 & 56.71
\end{tabular}

Health Behaviors: In the past 30 days

\begin{tabular}{lllll} 
14 or more days, no physical activity $(\mathrm{N}=1,604)$ & 736 & 45.89 & 868 & 54.11 \\
\hline Less than 14 days, no physical activity $(\mathrm{N}=3,586)$ & 1,649 & 45.98 & 1,937 & 54.02 \\
\hline Current smoker / Yes $(\mathrm{N}=572)$ & 298 & 52.10 & 274 & 47.90 \\
\hline Current smoker / No (N=4,593) & 2,079 & 45.26 & 2,514 & 54.74 \\
\hline At least one drink of alcohol / Yes (N=2,207) & 1,010 & 45.76 & 1,197 & 54.24 \\
\hline At least one drink of alcohol / No (N=2,960) & 1,368 & 46.22 & 1,592 & 53.78 \\
\hline Multiple drinks on one occasion / Yes (N=576) & 281 & 48.78 & 295 & 51.22 \\
\hline Multiple drinks on one occasion / No (N=4452) & 2,021 & 45.77 & 2,395 & 54.23 \\
\hline SRH $^{*}$ & & & &
\end{tabular}

\begin{tabular}{lllll} 
Excellent/ Very Good / Good $(\mathrm{N}=3,965)$ & 1,787 & 45.07 & 2,178 & 54.93 \\
\hline Fair / Poor $(\mathrm{N}=1,230)$ & 602 & 48.94 & 628 & 51.06
\end{tabular}

Physical Health not good, 14 or more days

$\begin{array}{lllll}\text { Yes }(\mathrm{N}=806) & 410 & 50.87 & 396 & 49.13 \\ \text { No }(\mathrm{N}=3,998) & 1,807 & 45.20 & 2,191 & 54.80\end{array}$

Mental Health not good, 14 or more days

$\begin{array}{lllll}\text { Yes }(\mathrm{N}=703) & 375 & 53.34 & 328 & 46.66 \\ \text { No }(\mathrm{N}=4,094) & 1,836 & 44.85 & 2,258 & 55.15\end{array}$

Note: New item 'Have you experienced the death of a family member or close friend in the years 2018 or 2019? * SOGI\$, CIS Gender includes 'I think of myself as straight and not transgender.'SOGI\$, all other includes Gay /Bisexual /Something else and transgender (male to female, female to male, gender nonconforming). $\mathrm{NH}^{€}=$ Non-Hispanic. $\mathrm{SRH}^{¥}$ Self-rated health 5 categories: excellent, very good, good, fair, and poor. Health behaviors reflect Healthy People 2020 target areas described in https://www.healthypeople.gov/2020/topics-objectives; accessed April 11,2021. For wording of survey items see 2019 BRFSS Questionnaire https://www.cdc.gov/brfss/questionnaires/index.htm; accessed May 14, 2021.

Table 3 compares the bereaved population size obtained by two different strategies. Complete Case Analyses (CCA) applies the sampling weights but ignores missing responses, while Multiple Imputation applies the sampling weights and uses MICE to complete missing responses. With CCA, the size of the 
population (i.e., the denominator) varies from 4,937,056 to 5,369,035 persons. When compared to U.S. Census bureau data, CCA underestimates the size of the Georgia population aged 18 years and older by 33.8 percent to 39.1 percent. By contrast, the combination of sampling weights with $\mathrm{Ml}$ techniques creates a base population of $8,164,018$. This is 0.6 percent larger than the U.S. Census bureau estimate of $8,113,542$ adults aged 18 years and older in Georgia.

Table 3: Percent Bereavement item within subgroups. 2019 Georgia BRFSS, Weighted data without imputation (Complete Case Analyses) and Weighted data with Multiple Imputation 


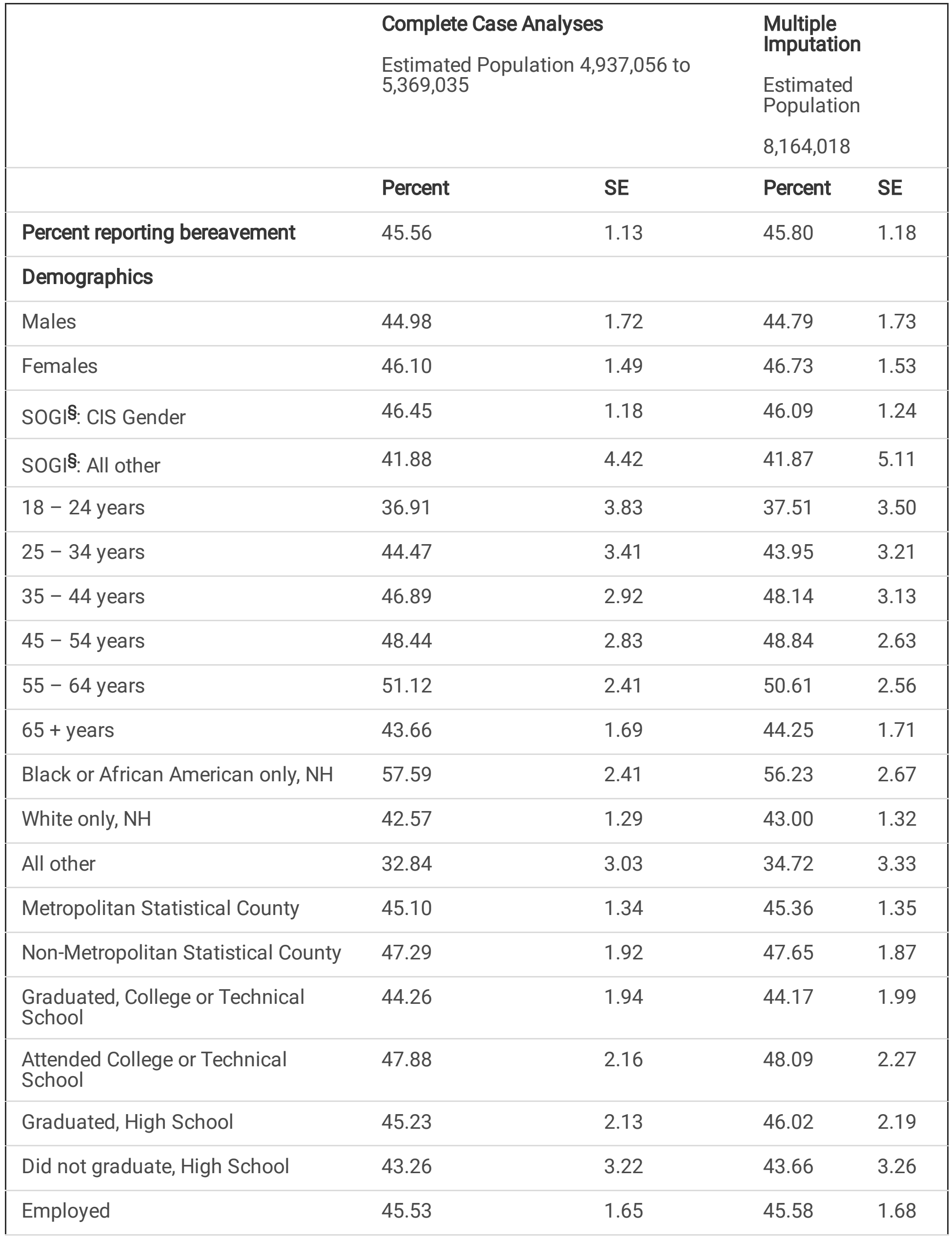




\begin{tabular}{|c|c|c|c|c|}
\hline Unemployed & 48.01 & 5.14 & 49.08 & 5.74 \\
\hline Retired & 45.27 & 1.84 & 45.56 & 1.92 \\
\hline Unable to work & 52.06 & 3.37 & 51.89 & 3.20 \\
\hline Homemaker or student & 41.22 & 3.58 & 41.50 & 3.33 \\
\hline \multicolumn{5}{|c|}{ High risk states of Health Behaviors in past 30 days } \\
\hline $\begin{array}{l}14 \text { or more days / No physical } \\
\text { activity }\end{array}$ & 46.04 & 2.07 & 46.21 & 1.99 \\
\hline Current smoker / Yes & 54.57 & 3.07 & 53.24 & 3.12 \\
\hline $\begin{array}{l}\text { Multiple drinks on one occasion / } \\
\text { Yes }\end{array}$ & 47.50 & 3.23 & 47.23 & 3.19 \\
\hline SRH / Fair / Poor & 51.74 & 2.35 & 50.88 & 2.31 \\
\hline $\begin{array}{l}14 \text { or more days, Physical health not } \\
\text { good }\end{array}$ & 54.02 & 2.80 & 52.79 & 2.67 \\
\hline $\begin{array}{l}14 \text { or more days/ Mental health not } \\
\text { good }\end{array}$ & 56.52 & 3.07 & 54.79 & 2.68 \\
\hline \multicolumn{5}{|c|}{ 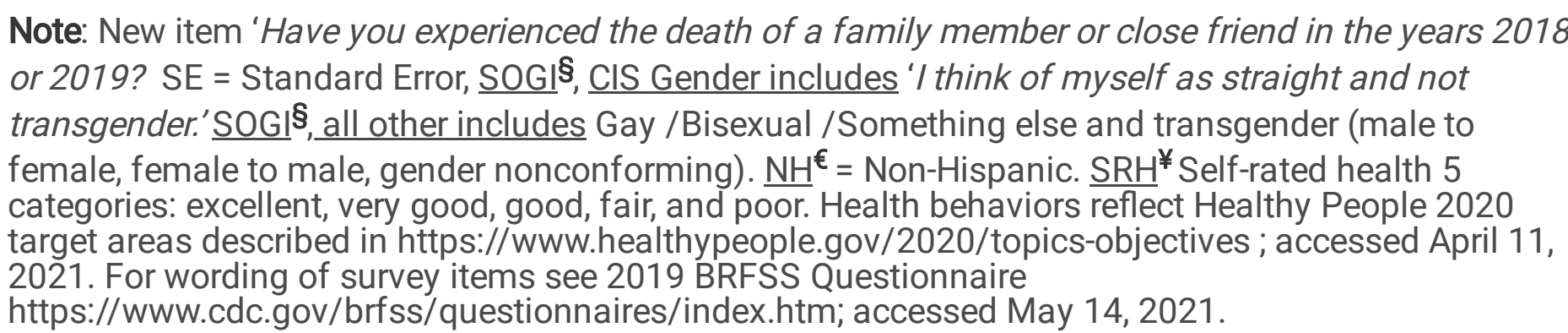 } \\
\hline
\end{tabular}

The MI derived prevalence estimates accommodate models that use two or more items that have missing responses. APPENDIX Table A shows two approaches to calculating 95 percent confidence interval using the unweighted, panel data. The Clopper-Pearson method ${ }^{14}$ and the Korn-Graubard method ${ }^{15}$ yield similar results for no missing responses (Gender), low rates of missing (Race, $<3 \%$ ), intermediate rates of missing (Binge drinking, 11\%) and high rates of missing data. This analysis is provided for readers interested in confidence intervals rather than standard errors.

Table three shows standard errors (SE) to illustrate MI and bereavement variance. There appear to be cross cutting effects. To illustrate this effect, consider the categories with missing responses to demographic items - SOGI, race, employment. With MI, almost all have larger standard errors. These items used to determine the sample size from recruited from each statistical county. Ml appears to have the opposite effect on bereavement prevalence variance in categories of health behavior. These SE are smaller than the ones derived from CCA. APPENDIX Table B contains odds ratios for high-risk health 
behaviors comparing the bereaved to those without recent bereavement with age and race adjusted models. This table was developed to illustrate the possible effects of variance. Based on the odds ratios and 95 percent confidence intervals, there may be an increased risk for these behaviors. Further analyses are required.

For work in public health and policy, the priority application of BRFSS is its use in products like the report Healthy People, 2020. This is a centennial report evaluating progress towards population health goals. Population health risk such as physical inactivity, smoking, alcohol abuse, and poor physical, mental, or self-rated health are the types of behaviors evaluated for changes during the time between reports. The longitudinal change modeling required for Healthy People reports is based on stable estimates and low variance. The Health Behavior category in Table 3 compares bereavement prevalence and the associated variance derived by the two techniques - CCA and MI. In the health behavior category, CCA appears to inflate prevalence and diminish precision. This trend will need to be revisited in subsequent survey years. Missing responses appears to favor $\mathrm{MI}$ rather than CCA.

\section{Discussion}

We present analyses from a module designed to measure new bereavement in a state-wide surveillance survey. As far as is known, there are no other population-based estimates for the likelihood of bereavement in a 24-month period that can be used for comparison. BRFSS is an annual cross-sectional survey. To begin evaluation of this new module, the report presents three valid approaches to analysis of BRFSS - unweighted panel data, weighted data, and weighted data using multiple imputation to add missing responses. These treatments provide prevalence and variance estimates under a variety of statistical assumptions. Further field testing is needed to replicate the stability of these estimates. Without comparison data, statistical strategies and their underlying assumptions become a critical starting point. For readers seeking technical details associated with the execution of BRFSS can be obtained from the CDC website.

The need to measure the accuracy and precision of this new exposure is based on evidence that it can add as much as a two-fold increased risk for negative health outcomes. Among cohorts aged 50 years and older, the population attributable risk for mortality risk is an estimated 5 percent. ${ }^{2}$ There is a 2 -fold increase in overnight hospital stays. ${ }^{1}$ The short and long-term economic consequences are well documented. ${ }^{16,17}$ During childhood, death of a parent threatens health and economic security well into adult life. ${ }^{18,19,20}$ These smaller scale studies indicate the potential for bereavement to operate as an emerging risk factor leading to declines in population health.

\section{Conclusion}

New bereavement can be ascertained in a surveillance survey without bias due to refusals. Multiple imputation provides a population that is comparable to U.S. Census bureau estimates. More field testing is required to replicate these results in other states. 


\section{Abbreviations}

GA BRFSS

Georgia Behavioral Risk Factor Surveillance Survey

US

United States

SOGI

Item in the GA BRFSS, Sexual Orientation and Gender Identity. Categories - SOGI CIS Gender 'I think of myself as straight and not transgender.'SOGI All others:Includes Gay / Bisexual/ Something else and transgender (male to female, female to male, gender nonconforming).

MCAR

Missing completely at random

MAR

Missing at random

MNAR

Missing not at random

MICE

Multiple imputation by chained equations

CCA

Complete case analyses

MI

Multiple Imputation

\section{Declarations}

- Ethics approval and consent to participate: The methods used in this survey were carried out in accordance with the Declaration of Helsinki guidelines and regulations. Consent to participate is implied by continued engagement in the telephone interview. All items are reviewed and approved by either the U.S. Office of Management and Budget or the State Department of Public Health.

- Consent for publication: BRFSS is anonymized, publicly available data.

- Availability of data and materials: The Centers for Disease Control and Prevention contain BRFSS data and related guidance.

- Competing interests: There are no competing / conflicting interests.

- Funding: The RRF Foundation for Aging provided support for the inclusion of the bereavement module in Georgia (https://www.rrf.org/)

- Authors' contributions:

- Miles: Originator of concept, author, and interpretation of data

- Changle Li: Author, originator of imputation techniques, and interpretation of data

- Ye Shen: Collaboration on imputation technique and interpretation of these analyses. 
- Rana Bayakly, Moges Ido: Georgia Department of Public Health, created analytic dataset, reviewed, and approved interpretation.

- Mahmoud Khan: Collaborator on concept of bereavement and risk.

- Acknowledgements: The RRF foundation for support and encouragement. Also, Joyal Mulheron, at Evermore (https://live-evermore.org/) for providing interim reviews of the results. Deborah Carr, Boston University for review and commentary on children and adolescent bereavement.

Ethics approval was waived by the Georgia IRB because this is publicly available data.

DATA AVAILABILITY: These data can be obtained from Rana Bayakly (Georgia, Department of Public Health).

\section{References}

1. Miles TP, Allegra JC, Ezeamama A, Simpson C, Gerst-Emerson K, Elkins J. 2016. In a longevity society, loss and grief are emerging risk factors for health care use: findings from the Health and Retirement Survey cohort aged 50 to 70 years. American $\mathrm{J}$ of Hospice and Palliative, https://doi.org/10.1177/1049909114552125

2. Allegra JC, Ezeamama A, Simpson C, Miles TP. 2015. Population-level impact of loss on survivor mortality risk. Quality of Life Research, https://doi.org/10.1007/s11136-015-1048-x

3. Health Care Spending and the Medicare Program: A Data Book, July 2020. Medicare Payment Advisory Commission.

4. Hughes RA, Heron J, Sterne JAC, Tilling K. 2019. Accounting for missing data in statistical analyses: multiple imputation is not always the answer. International $\mathrm{J}$ Epidemiology https://doi.org/10.1093/ije/dyz032

5. Harel O, Mitchell EM, Perkins NJ, Cole SR, Tchetgen EJT, Sun B, Schisterman EF. 2018. Multiple imputation for incomplete data in epidemiologic studies. American $\mathrm{J}$ Epidemiology. https://doi.org/10.1093/aje/kwx349

6. Rubin DB. 1976. Inference and missing data. Biometrika. https://doi.org/10.2307/2335739

7. Carpenter and Kenward 2012. Multiple imputation and its application. John Wiley \& Sons, Ltd. https:// doi.org/10.1002/9781119942283

8. Penn DA. 2007. Estimating missing values from the general social survey: an application of multiple imputation. Department of Economics and Finance Working Paper Series, JEL Categories: A10, C42.

9. Rubin DB. 2004. Multiple imputation for nonresponse in surveys. . John Wiley \& Sons, Ltd. ISBN: 978-0-471-65574-9

10. Kenward MG, Carpenter J. 2007. Multiple imputation: current perspectives. Statistical Methods Medical Research. https://doi.org/10.1177/0962280206075304

11. Horton NJ, Lipsitz SR. 2001. Multiple imputation in practice: comparison of software packages for regression models with missing variables. The American 
Statistician https://doi.org/10.1198/000313001317098266

12. StataCorp. 2017. Stata Statistical Software: Release 15. College Station, TX: StataCorp LLC.

13. White IR, Royston P, Wood AM. 2011. Multiple imputation using chained equations: issues and guidance for practice. Statistics in Medicine. https://doi.org/10.1002/sim.4067

14. Clopper CJ, Pearson ES. 1934. The Use of Confidence or Fiducial Limits Illustrated in the Case of the Binomial. https://www.jstor.org/stable/2331986

15. Korn EL, Graubard BI. 1999. Analysis of Health Surveys. Wiley Series in Probability and Statistics. ISBN-13: 978-0471137733

16. Gillen M, Kim H. 2009. Older women and poverty transition: consequences of income source changes from widowhood. J Applied Gerontology. https://doi.org/10.1177/0733464808326953

17. Li J, Vestergaard M, Cnattingius S, Gissler M, Bech BH, Obel C, Olsen J. 2014. Mortality after parental death in childhood: a nationwide cohort study from three Nordic countries. PloS Med. https://doi.org/10.1371/journal.pmed.1001679

18. Brent DA, Melhem NM, Masten AS, Porta G, Payne NW. 2012. Longitudinal effects of parental bereavement on adolescent developmental competence. J Clinical Child \& Adolescent Psychology. https://doi.org/10.1080/15374416.2012.717871

19. Feigelman W, Rosen Z, Joiner T, Silva C, Mueller AS. 2017. Examining longer-term effects of parental death in adolescents and young adults: evidence from the national longitudinal survey of adolescent to adult. Death Studies. https://doi.org10.1080/07481187.2016.1226990

20. Weaver DA. 2019. Parental mortality and outcomes among minor and adult children. Population Review. https://doi.org/10.1353/prv.2019.0006

\section{Supplementary Files}

This is a list of supplementary files associated with this preprint. Click to download.

- APPENDIXTABLEAAUGUST8.docx

- APPENDIXTABLEBAUGUST8.docx

- 2019GeorgiaBRFSS190413abtAsso22019QUESTIONNARE.docx

- HowtoUseHealthyPeople2030.pdf

- brfsshistory.pdf 